\title{
Age and Body Anthropometry as Predicting Factors for Carpal Tunnel Syndrome among Egyptian Obese Women
}

\author{
Moushira Zaki ${ }^{1 *}$, Maha $\mathrm{Ali}^{2}$, Walaa Yousef ${ }^{1}$, Wafaa Ezzat $^{2}$, Walaa Basha ${ }^{1}$ \\ ${ }^{1}$ Department of Biological Anthropology, National Research Centre, Cairo, Egypt, ${ }^{2}$ Department of Internal Medicine, National \\ Research Centre, Giza, Egypt
}

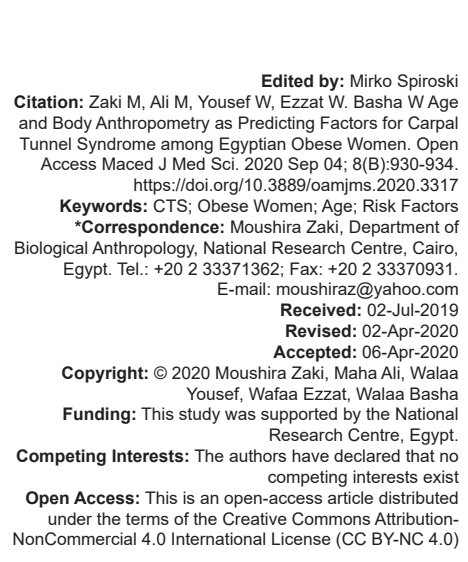

\section{Introduction}

Carpal tunnel syndrome (CTS) is a very widespread entrapment neuropathy [1]. It is occurred as a result of compression of the median nerve while it passes through the carpal tunnel [2] and could be reliably diagnosed by electrodiagnostic (EDX) (nerve conduction) studies. Symptoms involve pain and numbness, particularly at night, at the area of the median nerve in the affected hand which could extend to the entire upper limb. It has been previously observed that obesity and age over 30 years are the main factors which increased the risk for CTS. In addition, females, particularly pregnant, are the most affected gender. Medical conditions that increased the risk for CTS include hypothyroidism, rheumatoid arthritis, and osteoarthritis. Other behavioral and occupational factors such as typing and repetitive hand movements are involved as well [3], [4]. There are lots of studies that have explored the relationship between CTS and occupational activities which collected in systemic reviews that conducted by Barcenilla et al. [5], [6].

The purpose of this study was to evaluate the impact of age and body anthropometry on the incidence of CTS and recognize patients at high risk for CTS among Egyptian obese women.

\section{Patients and Methods}

The study included 120 obese women grouped according to their clinical and EDX findings into two groups: 60 with CTS and 60 Non-CTS. Ninety percent of the patients were housewives in both groups. There was no statistically significant difference between both groups as regards occupation. 


\section{Inclusion criteria}

Obese women their body mass index $(\mathrm{BMI}) \geq 30 \mathrm{~kg} / \mathrm{m}^{2}$ with CTS and had no evidence of a generalized neuropathy or other clinical or electrodiagnostic abnormalities.

\section{Exclusion criteria}

Women suffering from diabetes, the duration of symptoms <1 year, pregnant woman, under-treatment of cardiac arrhythmia, or muscle relaxant drugs and older than 50 years of age were excluded from the study.

\section{Anthropometric and clinical measurements}

Body weight, height, waist circumference (WC), hip circumference $(\mathrm{HC})$, and mid-upper arm circumference (MUAC) were measured for all cases. Body weight was measured to the nearest $0.1 \mathrm{~kg}$ and height was measured to the nearest $0.1 \mathrm{~cm}$. BMI was calculated as weight in kilograms divided by height in meters square $\left(\mathrm{kg} / \mathrm{m}^{2}\right)$.

A questionnaire, inquiring about age and CTS symptoms, has been taken. Clinical examination using both Tinel and Phalen signs, as previously described [7], has been performed for all cases. The pain was assessed by the visual analog scale. The linear scale represents the range of pain that a subject thought she might experience. Usually, the line is $10 \mathrm{~cm}$ in length with one end represents "no pain," while the other represents the worst pain. Every woman draws a mark on the line that represents the level of pain being experienced.

\section{Neurophysiological examination}

EDX study has been used in the diagnosis of median nerve entrapment at the level of the wrist, according to the American Association of Neuromuscular and EDX Medicine [8]. The median nerve, both motor and sensory, conduction studies to all cases have been performed as well as needle electromyography of the abductor pollicis brevis muscle to selected cases for evaluation of CTS severity using Deymed TRUTRACE EMG NCV 4 Channel System machine (AU712060002) at the EMG unit of the Medical Center of Scientific Excellence of NRC.

Comparison tests with neighboring nerves have been performed to cases showed clinical symptoms of CTS but normal or equivocal results of median sensory distal latency and motor distal latency.

The recommended comparative tests are the median-ulnar palmar mixed comparison study, the median-ulnar ring finger sensory study, or the medianulnar second lumbrical-interossei study. The diagnosis of CTS was confirmed if one, and preferably two, of these tests, were abnormal. If the results of these tests are normal, CTS is almost excluded [9].

\section{Ethical approval}

The research was approved by the Ethical Committee of NRC (No: 16361) and followed the World Medical Association's Declaration of Helsinki. Furthermore, each participant in the study signed a written consent after a full description of the study.

\section{Statistical analysis}

The Kolmogorov-Smirnov test was used to test the sample distribution. The appropriate test, either Student's t-tests or Mann-Whitney, was used for the continuous variables and the Chi-square and Fisher exact tests were used for percentages.

The receiver operating characteristic $(\mathrm{ROC})$ curve was used to determine the predictive value of age and body measures for the diagnosis of CTS and to compare their diagnostic power in discriminating CTS from non-CTS.

\section{Results}

The present data revealed that bilateral carpal tunnel CTS was found in $31.8 \%$ of cases and unilateral in $68.2 \%$. Most of them were right-sided. The dominant hand was affected first and produces the most severe pain.

A significant difference in the mean age has been found between the two studied groups and a tendency for higher body anthropometry measures in the CTS compared to non-CTS cases, as shown in Table 1.

Table 1: Age and body anthropometry in CTS and non-CTS cases

\begin{tabular}{llll}
\hline Variables & CTS $($ Mean \pm SD $)$ & Non-CTS $($ Mean \pm SD) & -value \\
\hline Age $($ years $)$ & $42.12 \pm 4.6$ & $34.61 \pm 7.3$ & 0.001 \\
BMI $\left(\mathrm{Kg} / \mathrm{m}^{2}\right)$ & $33.9 \pm 6.5$ & $30.9 \pm 8.0$ & 0.13 \\
WHR & $0.84 \pm 0.04$ & $0.77 \pm 0.05$ & 0.10 \\
WC $(\mathrm{cm})$ & $96.77 \pm 12.1$ & $88.00 \pm 14.3$ & 0.06 \\
HC $(\mathrm{cm})$ & $117.06 \pm 11.9$ & $109.94 \pm 13.7$ & 0.12 \\
MUAC $(\mathrm{cm})$ & $33.4 \pm 4.2$ & $30.93 \pm 6.4$ & 0.2 \\
\hline BMI: Body mass index, WHR: Waist-hip ratio, WC: Waist circumference, HC: Hip circumference,
\end{tabular}

BMI: Body mass index, WHR: Waist-hip ratio, WC: Waist circumference, HC: Hip circumference, MUAC: Mid upper arm circumference.

CTS cases showed significantly lower values of median motor nerve conduction velocity (MMNCV) and median sensory nerve conduction velocity relative to the non-CTS group. Significantly higher values of median sensory latency and median motor latency have been found in CTS compared to non-CTS cases, as presented in Table 2.

Table 2: Median nerve conduction parameters in CTS cases and non-CTS individuals।

\begin{tabular}{lll}
\hline Median nerve conduction parameters & CTS $($ Mean \pm SD $)$ & Non-CTS $($ Mean \pm SD) \\
\hline MMNCV $(\mathrm{m} / \mathrm{s})$ & $49.59 \pm 7.7^{\star \star}$ & $59.23 \pm 4.1$ \\
MML $(\mathrm{ms})$ & $4.84 \pm 1.3^{* \star}$ & $3.23 \pm 0.3$ \\
MSNCV $(\mathrm{m} / \mathrm{s})$ & $46.31 \pm 7.1^{\star \star}$ & $53.01 \pm 4.3$ \\
MSL $(\mathrm{ms})$ & $4.6 \pm 1.4^{\star *}$ & $3.1 \pm 0.09$ \\
\hline MMNCV: Median motor nerve conduction velocity, MML: Median motor latency, MSNCV: Median sensory \\
nerve conduction velocity, MSL: Median sensory latency. ${ }^{*} p<0.05,{ }^{* *} p<0.01$.
\end{tabular}


Table 3 shows the partial correlations between body anthropometry and the nerve conduction parameters. Negative correlations were found between MMNCV and anthropometric measures.

Table 3: Partial correlations between body anthropometry and median nerve conduction findings, adjusted for age

\begin{tabular}{llllll}
\hline Median nerve conduction findings & $\mathrm{BMI}(\mathrm{r})$ & WHR( $\mathrm{r})$ & $\mathrm{WC}(\mathrm{r})$ & $\mathrm{HC}(\mathrm{r})$ & $\mathrm{MUAC}(\mathrm{r})$ \\
\hline MMNCV & $-0.42^{*}$ & $-0.72^{* *}$ & $-0.51^{* *}$ & -0.27 & -0.32 \\
MML & -0.09 & 0.16 & 0.02 & -0.05 & 0.014 \\
MSNCV & 0.13 & -0.12 & 0.051 & 0.13 & 0.04 \\
MSL & -0.14 & 0.17 & -0.05 & -0.15 & -0.06 \\
\hline MMNCV: Median motor nerve conduction velocity, MML: Median motor latency, MSNCV: Median sensory \\
nerve conduction velocity, MSL: Median sensory latency, BMI: Body mass index, WHR: Waist-hip ratio, \\
WC: Waist circumference, HC: Hip circumference, MUAC: Mid upper arm circumference. r=correlation
\end{tabular}
coefficient, $p<0.05, " p<0.0$

The areas under the ROC curve were presented in Table 4 with age showed the highest areas under the ROC curve, followed by BMI, waistto-hip ratio (WHR) WC, HC, and MUAC. ROC curves of the age and body anthropometry in detecting the presence of CTS in Egyptian women are shown in Figure 1 and Figure 2.

Table 4: Area under the receiver operating characteristic curve (AUC) for age, anthropometric measurements of the studied participants

\begin{tabular}{lllll}
\hline Variables & AUC & Cutoff points & Sensitivity $(\%)$ & Specificity (\%) \\
\hline Age (years) & 0.811 & 40.5 & 77 & 75 \\
BMI (Kg/m $\left.{ }^{2}\right)$ & 0.680 & 30.25 & 75 & 59 \\
WHR & 0.680 & 0.796 & 82 & 53 \\
WC $(\mathrm{cm})$ & 0.671 & 91 & 75 & 65 \\
HC $(\mathrm{cm})$ & 0.662 & 113.5 & 69 & 71 \\
MUAC $(\mathrm{cm})$ & 0.642 & 30.5 & 69 & 53 \\
\hline AUC: Area under the curve, BMl: Body mass index, WHR: Waist-hip ratio, WC: Waist circumference,
\end{tabular}

HC: Hip circumference, MUAC: Mid upper arm circumference.

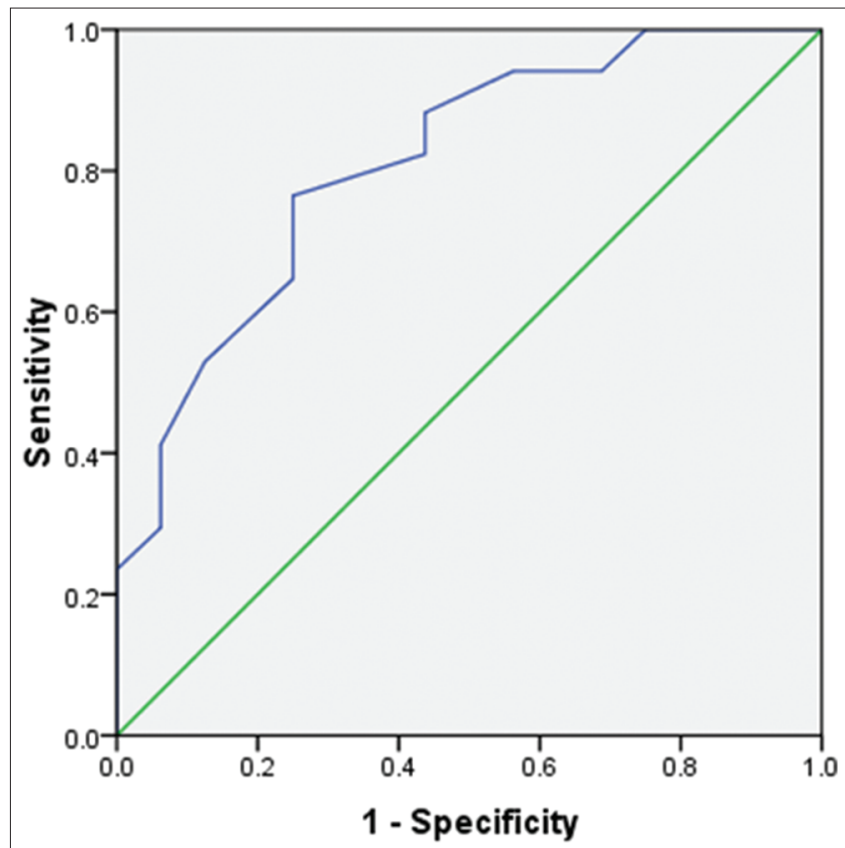

Diagonal segments are produced by ties.

Figure 1: Receiver operating characteristic curve of age in detecting the presence of carpal tunnel syndrome in Egyptian women

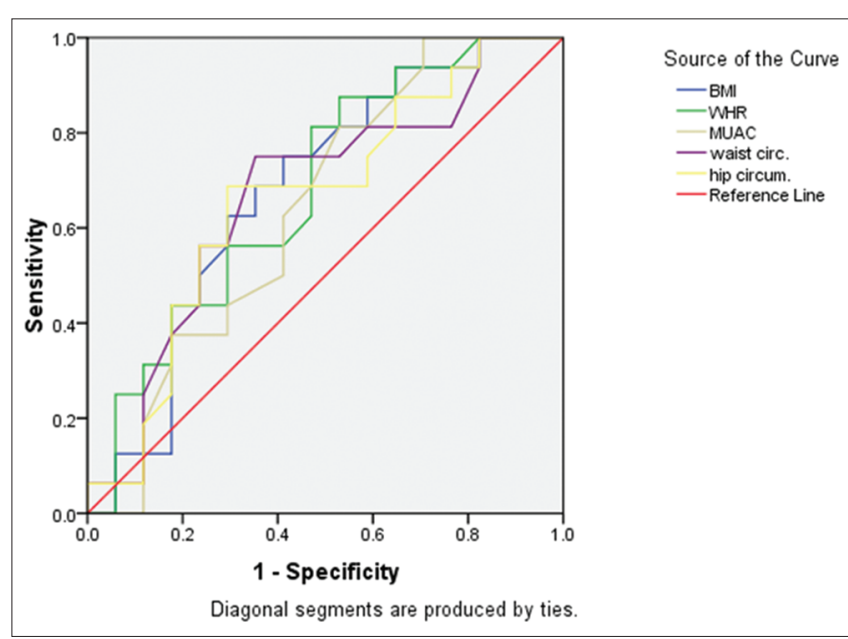

Figure 2: Receiver operating characteristic curve of body mass index, waist-hip ratio, mid-upper arm circumference, waist circumference, and hip circumference in detecting the presence of carpal tunnel syndrome in Egyptian women.

\section{Discussion}

The incidence of CTS was previously estimated in different populations. A very wide occurrence range has been reported where the prevalence is varied in different populations and highly affected by the type of occupation [10]. EDX studies have been considered as a gold standard for CTS diagnosis [11], [12], [13]. CTS is typically presented with pain and/or dysesthesia of the fingers that might spread throughout the hand and radiate to the wrist. Symptoms usually become worse at night or in the early morning. In severe cases, atrophy of the thenar eminence and/or weakness of thumb abduction and opposition could be observed [13].

Results of the present study showed significant age differences between the two groups; CTS cases were significantly older compared with non-CTS. We found that age $>40.5$ years (area under the curve $[A U C]=0.81,77 \%$ sensitivity and $75 \%$ specificity) is a very important risk factor for CTS in obese females. It has been previously found that the age of $41-60$ years is an independent risk factor for CTS which agreed with our results [3]. Although in the present study there were no significant differences in anthropometric measurements between the two groups, the CTS group tends to have higher anthropometric measurements (BMI, WC, WHR, $\mathrm{HC}$, and MUAC). This might indicate the association between the severity of obesity and the developing of CTS. It has been previously shown that body mass index and obesity are strongly associated with CTS, with every one-unit increase in body mass increasing the risk of the condition by $8 \%$ [14]. The statistically significant correlation between age, obesity, and CTS has been reported previously by Tunç and Güngen (2017). The association between obesity and CTS might be explained as follow; the compressive effect on the median nerve could result from the accumulation 
of fat tissue inside the carpal tunnel or an increase in hydrostatic pressure through this canal [3]. Moreover, the high carpal tunnel pressure may lead to fibrosis and thickening of the subsynovial connective tissue in the canal [15], [16]. The association between body anthropometry and CTS has been previously found; however, the anthropometric measurements were of low accuracy and had limited value as diagnostic tools for CTS [17]. This is consistent with our results where the AUC for the anthropometric measurements is ranging from 0.64 to 0.68 .

Factors that have also been suggested to increase the risk for CTS include females in their first menopausal year and those taking the oral contraceptive pill or taking hormone replacement therapy [18].

Regarding the relationship between anthropometric measurements and median nerve conduction parameters, the present study showed that anthropometric measurements are negatively correlated with MMNCV. WHR is the anthropometric measurement that showed the strongest correlation. However, a study that has been done by Majumdar et al. [19] found negative correlations between BMI, WHR, and MMNCV in a sample of obese subjects who are not suffering from CTS. Hence, it has been suggested that obese individuals might suffer from the slowing of motor nerve conduction and this biological factor should be considered [19]. We can suggest that anthropometric measurements and age have to be taken into considerations while interpreting nerve conduction studies and they can be measured as important factors in CTS cases under the same occupational settings and stresses.

There are some limitations to this study. The relatively small sample size and only investigated women.

\section{Conclusion}

Age and obesity are age and obesity indices can be used as predictors to CTS in obese women for CTS; age is more valuable as a diagnostic tool, though. Women with a high degree of obesity and above 40 years of age are particularly at high risk for CTS.

\section{References}

1. Werner RA, Andary M. Carpal tunnel syndrome: Pathophysiology and clinical neurophysiology. Clin Neurophysiol. 2002;113(9):1373-81. https://doi.org/10.1016/ s1388-2457(02)00169-4

PMid:12169318
2. Kouyoumdjian JA, Zanetta DM, Morita MP. Evaluation of age, body mass index, and wrist index as risk factors for carpal tunnel syndrome severity. Muscle Nerve. 2002;25(1):93-7. https://doi. org/10.1002/mus. 10007

PMid: 11754190

3. Becker J, Nora DB, Gomes I, Stringari FF, Seitensus R, Panosso JS, et al. An evaluation of gender, obesity, age and diabetes mellitus as risk factors for carpal tunnel syndrome. Clin Neurophysiol. 2002;113(9):1429-34. https://doi.org/10.1016/ s1388-2457(02)00201-8

PMid:12169324

4. Hendriks SH, van Dijk PR, Groenier KH, Houpt P, Bilo HJ, Kleefstra N. Type 2 diabetes seems not to be a risk factor for the carpal tunnel syndrome:A case control study. BMC Musculoskelet Disord. 2014;15:346. https://doi.org/10.1186/1471-2474-15-346 PMid:25315096

5. Barcenilla A, March LM, Chen JS, Sambrook PN. Carpal tunne syndrome and its relationship to occupation: A meta-analysis. Rheumatology. 2012;51(2):250-61. https://doi.org/10.1093/ rheumatology/ker108

PMid:21586523

6. Kozak A, Schedlbauer G, Wirth T, Euler U, Westermann C, Nienhaus A. Association between work-related biomechanical risk factors and the occurrence of carpal tunnel syndrome: An overview of systematic reviews and a meta-analysis of current research. BMC Musculoskelet Disord. 2015;16:231. https://doi. org/10.1186/s12891-015-0685-0

PMid:26323649

7. Phalen GS. The carpal-tunnel syndrome. Seventeen years experience in diagnosis and treatment of six hundred fifty-four hands. J Bone Joint Surg Am. 1966;48(2):211-28. https://doi. org/10.2106/00004623-196648020-00001

PMid:5934271

8. Wang L. Electrodiagnosis of carpal tunnel syndrome. Phys Med Rehabil Clin N Am. 2013;24(1):67-77.

PMid:23177031

9. Basiri K, Katirji B. Practical approach to electrodiagnosis of the carpal tunnel syndrome: A review. Adv Biomed Res. 2015;4:50. https://doi.org/10.4103/2277-9175.151552 PMid:25802819

10. Atroshi I, Gummesson C, Johnsson R, Ornstein E, Ranstam J, Rosén I. Prevalence of carpal tunnel syndrome in a general population. JAMA. 1999;282(2):153-8. https://doi.org/10.1001/ jama.282.2.153 PMid:10411196

11. Aroori S, Spence RA. Carpal tunnel syndrome. Ulster Med J. 2008;77(1):6-17.

PMid:18269111

12. Graham B. The value added by electrodiagnostic testing in the diagnosis of carpal tunnel syndrome. J Bone Joint Surg Am. 2008;90(12):2587-93. https://doi.org/10.2106/jbjs.g.01362 PMid:19047703

13. Ibrahim I, Khan WS, Goddard N, Smitham P. Carpal tunnel syndrome: A review of the recent literature. Open Orthop J. 2012;6:69-76. https://doi.org/10.2174/1874325001206010069 PMid:22470412

14. Nordstrom DL, Vierkant RA, DeStefano F, Layde PM. Risk factors for carpal tunnel syndrome in a general population. Occup Environ Med. 1997;54(10):734-40. https://doi. org/10.1136/oem.54.10.734

PMid:9404321

15. Tunç A, Güngen BD. Carpal tunnel syndrome: Investigating the sensitivity of initial-diagnosis with electro-diagnostic tests in 600 cases and associated risk factors especially manual 
milking. J Back Musculoskelet Rehabil. 2017;30(2):333-8. https://doi.org/10.3233/bmr-160547

PMid:27858695

16. Chiotis K, Dimisianos N, Rigopoulou A, Chrysanthopoulou A, Chroni E. Role of anthropometric characteristics in idiopathic carpal tunnel syndrome. Arch Phys Med Rehabil. 2013;94(4):737-44. https://doi.org/10.1016/j.apmr.2012.11.017 PMid:23178273

17. Mondelli M, Aretini A, Ginanneschi F, Greco G, Mattioli S. Waist circumference and waist-to-hip ratio in carpal tunnel syndrome: A case-control study. J Neurol Sci.
2014;338(1-2):207-13. https://doi.org/10.1016/j.jns.2014.01.012 PMid:24468538

18. Solomon DH, Katz JN, Bohn R, Mogun H, Avorn J. Nonoccupational risk factors for carpal tunnel syndrome. J Gen Intern Med. 1999;14(5):310-4. https://doi. org/10.1046/j.1525-1497.1999.00340.x

PMid:10337041

19. Majumdar S, Chaudhuri A, Ghar M, Rahaman WB, Hai A. Effect of obesity on nerve conduction study in an urban population of a developing country. Saudi J Sports Med. 2017;17:162-7. https:// doi.org/10.4103/sjsm.sjsm_8_17 